University of Nebraska - Lincoln

DigitalCommons@University of Nebraska - Lincoln

1996

\title{
Visual Search for Natural Grains in Pigeons (Columba livia) : Search Images and Selective Attention
}

\author{
Cynthia M. Langley \\ University of California, Berkeley \\ Donald A. Riley \\ University of California, Berkeley, dariley@berkeley.edu \\ Alan B. Bond \\ University of Nebraska - Lincoln, abond1@unl.edu \\ Namni Goel \\ University of Michigan, goel@mail.med.upenn.edu
}

Follow this and additional works at: https://digitalcommons.unl.edu/bioscibehavior

Part of the Behavior and Ethology Commons

Langley, Cynthia M.; Riley, Donald A.; Bond, Alan B.; and Goel, Namni, "Visual Search for Natural Grains in Pigeons (Columba livia) : Search Images and Selective Attention" (1996). Papers in Behavior and Biological Sciences. 49.

https://digitalcommons.unl.edu/bioscibehavior/49

This Article is brought to you for free and open access by the Papers in the Biological Sciences at DigitalCommons@University of Nebraska - Lincoln. It has been accepted for inclusion in Papers in Behavior and Biological Sciences by an authorized administrator of DigitalCommons@University of Nebraska - Lincoln. 
Published in Journal of Experimental Psychology: Animal Behavior Processes 22:2 (1996) , pp. 139-151; doi: 10.1037/0097-7403.22.2.139

Copyright @ 1996 American Psychological Association. Used by permission. "This article may not exactly replicate the final version published in the APA journal. It is not the copy of record." http://www.apa.org/journals/xan/

\title{
Visual Search for Natural Grains in Pigeons (Columba livia) : Search Images and Selective Attention
}

\author{
Cynthia M. Langley, Department of Psychology, University of California, Berkeley \\ Donald A. Riley, Department of Psychology, University of California, Berkeley \\ Alan B. Bond, School of Biological Sciences, University of Nebraska-Lincoln \\ Namni Goel, Department of Psychology, University of Michigan \\ Corresponding author - Cynthia M. Langley, Department of Psychology, \\ Indiana University, Bloomington, Indiana 47405; email clangley@ucs.indiana.edu
}

\begin{abstract}
The experiments reported here were designed to test the suggestion of many researchers that selective attention to visual features of a prey can account for search-image effects. In 3 experiments pigeons ate wheat and vetch grains presented on multicolored and gray gravel trays. In Experiment 1 search-image effects were evident when grains were cryptic but not when they were conspicuous. Experiment 2 demonstrated that search images can be activated when the grains encountered are either cryptic or conspicuous but that search images affect search performance only when the grains are cryptic. Experiment 3 demonstrated that search images are short-term in nature: A 3-min delay between successive encounters with a type of grain disrupted an activated search image. The discussion addresses how these results further develop a model in which search images are viewed as selective attention to visual features of a prey.
\end{abstract}

Tinbergen (1960) coined the term search image to refer to a perceptual bias that he believed influenced the prey selection of great tits (Parus major) he observed in the Dutch pine woods. He noted that when the birds foraged on a familiar substrate for cryptic prey, they collected a variety of different species over a period of hours or days, but they tended to bring a single prey type to the nest during successive foraging bouts. Tinbergen (1960) suggested that these temporary selection biases were due to the birds' performing "a highly selective sieving operation on the stimuli reaching their retina" (p. 332) when searching for a specific prey type. He predicted that this process would improve the rate at which birds could collect prey by improving the birds' ability to discriminate prey from a substrate. Tinbergen also noted that the great tits selected the most common types of prey more frequently than they occurred in the environment. He suggested that a search image was activated for the most frequent prey type as a result of repeated chance encounters with that prey. Once a search image was activated, the bird was more likely to detect common prey than alternative prey types, thereby overselecting the common ones.

Search-image effects have been demonstrated in a variety of controlled experiments. Using a seminaturalistic task in which birds fed freely on several types of prey that were presented simultaneously, Dawkins (1971b) found that the chicks selected grains in runs: Long sequences of eating one color of grain were followed by long sequences of eating another color. Bond (1983) and Reid and Shettleworth (1992) found that when two types of grain were presented on a multicolored gravel tray, pigeons (Columba livia) selected the most common type of grain in greater proportion than it was represented. Bond (1983) also demonstrated that pigeons collected grain faster when overselection was apparent.

Tinbergen's (1960) search-image effects have also been demonstrated in serial-detection tasks, in which the sequence of prey that a bird encounters is controlled by the experimenter. In contrast to the seminaturalistic tasks described above, in which chance is assumed to affect repeated encounters with one prey type, serial-detection experiments provide direct evidence that repeated encounters with a prey can activate a search image. Blue jays (Cyanocitta cristata) were significantly more accurate at locating cryptic moths on photographic slides when the same type of prey was presented on successive trials than when prey types alternated randomly over trials (Pietrewicz \& Kamil, 1979).Pigeons were also significantly more accurate at locating cryptic grains in slide im-

The authors thank George W. Barlow, Stephen E. Glickman, and Sara Shettleworth for thoughtful critical comments on this article. This article is based, in part, on a thesis submitted to the University of California, Berkeley, in partial fulfillment of the requirements for the doctoral degree in psychology for Cynthia M. Langley. This article is also based, in part, on a senior honors thesis submitted to the University of California, Berkeley, for Namni Goel. The research was supported by U.S. Public Health Service Grant RO1MH444746 and National Research Service Awards MH10360-01 and MH10662-01. 
ages when a single type of grain was presented over successive trials than when grain types alternated randomly over trials (Bond \& Riley, 1991). Reaction time to discover a cryptic target also improved after repeated encounters in Bond and Riley's (1991) study, as well as in a series of search-image experiments by Blough $(1989,1991,1992)$ in which pigeons searched for alphanumeric targets on a computer display.

A number of researchers have suggested that selective attention to visual features of a prey can account for searchimage effects (Blough, 1989, 1991, 1992; Bond, 1983; Bond \& Riley, 1991; Dawkins, 1971b; Pietrewicz \& Kamil, 1979; Reid \& Shettleworth, 1992).Psychologists' research on selective attention and their research on search images have been linked in at least four ways. One such link, pointed out by Blough $(1989,1991)$, is that the manipulations used to effect selective attention and search images are conceptually similar. To examine the effect of expectancy on search performance, selective attention experiments manipulate the information available to subjects about a forthcoming stimulus. When a cue, or prime, associated with a specific target is presented before a search display containing that target, human subjects locate the target faster than when no cue is provided (Posner \& Snyder, 1975).In search-image experiments, repeated encounters with a given prey item imply a high probability that this item will be present on the next opportunity to search. Repeated encounters thus operate as a prime in search-image experiments. Blough $(1989,1991)$ suggested that this sequential prime provides the bird with advance information about forthcoming prey items, which results in selective attention to visual features of a prey and improved search performance similar to that which occurs for human subjects provided with associative cue primes.

A second link between selective attention and search images is that the circumstances in which selective attention ought to influence performance are the circumstances in which search-image effects are observed. Riley and Roitblat (1978) argued that selective attention effects ought to be evident in experiments with animals when a discrimination task is difficult or when a lot of information must be processed before making a response, but not when the perceptual information processing load is low. Perceptual load is high for the searching animal when prey are cryptic. In order to be considered cryptic, a prey's color pattern must resemble a random sample of the varying sizes, shapes, colors, and brightnesses of the background where the prey is most vulnerable to visually hunting predators (Endler, 1984).Selective attention to a limited subset of visual features of a particular cryptic prey should tend to decrease the number of nonprey items that are scanned and thus decrease search time and increase the accuracy with which the prey is discriminated from the background. The relative advantage of hunting by search image should increase with the degree of resemblance between prey and background, and, in fact, search-image effects are evident when prey are cryptic but not when they are conspicuous (Bond, 1983; Bond \& Riley, 1991; Reid \& Shettleworth, 1992) .

As the two remaining links have been made between psychologists' research on selective attention and their research on search images, the concept of what a search image is has changed from that described by Tinbergen (1960).Tinbergen viewed the adoption of a search image as a process by which birds could "learn to see" a novel type of cryptic prey. Many studies of search-image effects have concentrated on the predator's initial acquisition of a feeding response to novel food types (Fullick \& Greenwood, 1979; Harvey, Birley, \& Blackstock, 1975) or on its learning to discriminate a familiar food in novel, cryptic circumstances (Dawkins, 1971a; Lawrence, 1985a, 1985b) .

Bond (1983) argued that although discrimination learning plays a role in predators' initially learning to detect prey in a novel, cryptic context, it cannot account for search-image effects evident during search for prey in familiar, cryptic circumstances. Unless the discrimination learning was fairly volatile, ensuring that the appearance of known food types could easily be forgotten, the animals would quickly learn to recognize the few types of prey presented in experimental investigations of search-image effects, would consume them in the same proportion in which they were presented, and would reach an asymptotic speed of detection from which they would not vary as a result of repeated encounters with one or the other type of prey. Evidence of rapidly established and reversible improvements in predators' ability to detect targets in familiar, cryptic circumstances supports a selective attention, as opposed to a discrimination learning, model of search-image effects (Blough, 1989, 1991, 1992; Bond, 1983; Bond \& Riley, 1991; Pietrewicz \& Kamil, 1979; Reid \& Shettleworth, 1992) .

A final bit of evidence suggests that search-image effects result from selective attention to a particular prey: Detection of visually dissimilar prey is attenuated when a search image is activated. Tinbergen (1960), reasoning from his belief that discrimination learning could account for search-image effects, argued that birds could simultaneously retain several search images. This prediction is contradicted by evidence that search-image effects are rapidly reversed by exposure to alternative prey types (Blough, 1989, 1991, 1992; Bond, 1983; Bond \& Riley, 1991; Pietrewicz \& Kamil, 1979; Reid \& Shettleworth, 1992).Not only is there evidence that no more than one search image can be activated at any one time, there is also evidence that an activated search image can attenuate the predator's ability to detect visually dissimilar prey (Blough, 1992; Bond \& Riley, 1991; Reid \& Shettleworth, 1992).Psychologists have argued that selective attention to the features of a target stimulus should increase a searcher's ability to detect that target at the cost of overlooking other targets (Sutherland \& Mackintosh, 1971).In research with humans, the selective attention mechanism activated by priming has filter-like properties that inhibit detection of alternative targets (Posner \& Snyder, 1975; see also Eriksen \& Yeh, 1985).The best evidence of attenuated detection of unprimed targets during search with nonhuman subjects comes from search-image experiments (Blough, 1992; Bond \& Riley, 1991; Reid \& Shettleworth, 1992) .

The current experiments were designed to further develop a model in which search images are viewed as selective attention to visual features of a specific prey. Evidence from the brief literature review just presented suggests that a search image is a perceptual expectancy set by repeated encounters with a particular type of prey. A high perceptual 
load is necessary for activation of a search image, for an active search image to affect search performance, or for both. Search-image effects cannot be accounted for by discrimination learning but can be conceptualized as shifts in selective attention. Finally, when a search image is active the searcher is less able to detect visually dissimilar prey than when no search image is active. We designed the experiments reported here to discover why a high perceptual load is necessary for the observation of search-image effects and to discover whether an activated search image will decay over time when the prey type matching the search image is not encountered - a prediction of Bond's (1983) attention threshold model of search images.

In Experiment 1 we attempted to replicate Bond's (1983) work with a new set of grains. The new grains, used in all of our experiments, were selected to be equally cryptic on multicolored gravel trays. A successful replication would provide a legitimate basis for comparison of our results with Bond's (1983) .

We conducted Experiment 2 to answer two questions. First, is prey crypticity necessary for the activation of a search image? It may be. Perhaps search images are activated when a predator discriminates between the visual features of a cryptic prey and the background. Alternatively, the activity of discriminating prey from background may not be critical in the activation of a search image: Successive exposures to conspicuous prey may be sufficient. Second, is prey crypticity necessary for a search image to affect search performance? If selective attention to visual features of a particular prey underlies search-image effects, then prey crypticity should be necessary to detect evidence of an active search image. An active search image heightens the predator's ability to detect visual features of a particular prey, which should allow it to more effectively discriminate the target prey from the cryptic background. The effects of a perceptual bias should not be evident, however, when perceptual load is very low. When perceptual load is very low, the pigeons' ability to detect both grain types should be at a ceiling and the presence of a perceptual bias for one grain type should not be demonstrable.

In Experiment 3 we tested a prediction of Bond's (1983) attention threshold model of search images. The attention threshold model suggests that there are two ways in which an activated search image can be disrupted: either by the predator's encountering alternative prey types or by its searching over a period of time and encountering no further prey matching the image. Previous experiments have demonstrated that visual predators can rapidly exchange one search image for another when the prey type changes (Bond, 1983; Bond \& Riley, 1991; Pietrewicz \& Kamil, 1979, 1981; Reid \& Shettleworth, 1992) , but it has not been demonstrated that it is the time delay between successive encounters that results in search-image decay.

\section{Experiment 1}

Experiment 1 was an attempt to replicate Bond's (1983) work with a new set of grains. In this experiment, pigeons consumed bean and wheat grains presented on gravel-covered trays. Half of the trays were covered with multicolored gravel, against which the grains were difficult for pigeons to detect. The remaining trays were painted light gray, against which both grain types were conspicuous. On various experimental trials, the trays contained either only one type of grain or both grain types in various relative proportions. We manipulated the likelihood of successive encounters with one grain type, and thus the likelihood of activating a search image, by changing the proportion of that grain type on the tray.

Experiment 1 was designed to control for two explanations of search-image effects that have been offered as alternatives to a selective attention account: the preference hypothesis and the stare-duration hypothesis. One effect of hunting by search image, overselection of the more common of two prey types, could occur because the predator develops a preference for the type encountered most frequently. Responses to a common prey type are rewarded by the very fact that the birds consume the prey items. If a change in preference for a frequently encountered grain was the cause of an overselection effect, then overselection should occur whether or not perceptual load is high. Bond (1983) was able to rule out the preference hypothesis as an explanation of his overselection effects because he presented grains on both multicolored and gray trays and found evidence of overselection only when the grains were cryptic. We included both multicolored and gray trays in Experiment 1 so that we could also rule out the preference hypothesis as an account of overselection if our results replicated Bond's (1983) .

The two grain types presented to pigeons in Experiment 1 were selected to be equally cryptic on the multicolored background so that we could rule out the stare-duration hypothesis as a potential explanation for improvements in search over successive encounters with a single grain type. Guilford and Dawkins's (1987) stare-duration hypothesis ${ }^{1}$ states that improvements in cryptic prey detection may occur when a predator learns to look longer at each area of a patch. If a short "look-time" at each successive area of a patch allows successful detection of less cryptic prey, it should be expected that longer look-times will be needed to detect more cryptic prey. If a bird searches for prey using short looktimes appropriate for less cryptic prey, it may fail to detect more cryptic items and therefore overselect less cryptic prey. If, when less cryptic prey become rare, the bird learns to adopt a longer look-time, then it will be better able to detect more cryptic prey. Thus, the stare-duration hypothesis could explain improvements in a predator's ability to detect cryptic prey over successive encounters in search situations where prey are not equally cryptic. Reid and Shettleworth (1992, Experiment 1) selected two equally cryptic grains in their replication of Bond's (1983) study in order to rule out the stare-duration hypothesis as an account of their results. We did the same in Experiment 1.

${ }^{1}$ Endler (1991) noted that Guilford has agreed, in retrospect, that the Guilford and Dawkins (1987) search-rate hypothesis can be more accurately called the stare-duration hypothesis. 
We measured selection bias, peck accuracy, and peck rate in each experimental condition, following Bond (1983) and Reid and Shettleworth (1992).We also recorded the amount of time a bird scanned the tray prior to its first peck. Search images were expected to be evident on multicolored trays: Grain selection and speed of grain capture were expected to vary as a function of the proportion of grain presented. Neither grain selection nor speed of grain capture was predicted to vary as a function of proportion on gray trays.

\section{Method}

\section{Subjects}

Four female pigeons (Columba livia) participated in Experiment 1. All 4 birds were maintained in individual cages at $80-85 \%$ of their free-feeding weight. Subjects were maintained throughout the experiment in a 12:12-hr light-dark cycle with lights on at 6:00 A.M. and were tested between 2 and $6 \mathrm{hr}$ after light onset. Subjects were naive at the commencement of training.

\section{Gravel Trays}

Trays were covered with beach gravel between $3 \mathrm{~mm}$ and $7 \mathrm{~mm}$ in diameter. The gravel was picked over, and pieces of shell, glass chips, and pottery were eliminated. Thoroughly washed gravel (500 cc) was mixed with about $80 \mathrm{cc}$ of clear casting resin and poured over a $9.5 \times 20.7 \mathrm{~cm}$ piece of plywood. The mixture was spread evenly to a depth of about $1 \mathrm{~cm}$ and allowed to harden. The result was a hard, glossy surface with as much as $5-7 \mathrm{~mm}$ of relief between the height of peaks and troughs. We subsequently applied three coats of clear, satin-finish Varathane to the surface to reduce reflectance. The predominant color of the gravel was yellow-orange, but there were large components of black, red-brown, brown, tan, and white gravel pieces. A total of 24 pans containing this multicolored gravel were prepared. Another 24 pans were treated similarly, but instead of clear Varathane, they were given two coats of machine-gray spray enamel, followed by a light coat of gloss white. This painting technique produced a uniform, palegray surface against which all of the experimental stimuli were readily visible. In subsequent references, this is termed the gray background.

\section{Stimuli}

The stimuli used for the experiment were grains of two different species of plants: red wheat (Triticum durum) and common vetch (Vicia sativa).Both grains are readily eaten by pigeons. The wheat and vetch seeds bear little resemblance to each other. Red wheat is yellow-red in color and ovoid in shape. The red wheat was sifted through a 3.35-mm sieve (Fisher No. 6), and the large seeds (about $2.5 \times 7 \mathrm{~mm}$ ) retained for use were always placed on the tray with the conspicuous ventral furrow downwards and concealed from view. Common vetch is round and uniformly brown in color. We obtained uniform-sized common vetch seeds by sifting samples through a 4.75-mm sieve (Fisher No. 4) and a 4-mm sieve (Fisher No. 5), retaining those that passed through the larger, but not the smaller, sieve.

\section{Stimulus Positioning}

Prior to placement of the grains on gravel trays, a computerrandomized list was generated that determined which 20 multicolored or gray trays were to be used that day and in what or- der they would be presented to the pigeons. The computer also generated an independently randomized list of wire tray masks. These wire masks, the same size as the gravel trays, each contained 20 randomly distributed holes which we used as guides while placing grains on trays to ensure that the grains would be randomly distributed across the tray and that the feeding behavior of the pigeons would be free of spatial artifacts. The masks ensured that a minimum spacing of $1.5 \mathrm{~cm}$ was maintained between adjacent grains. This spacing reduced the likelihood of multiple, simultaneous discoveries. The 20 different masks used in the experiment represented 80 different distributions in which seeds could be placed on the trays (each mask could be placed in four separate orientations relative to the tray).For each trial, a sample of 20 grains was distributed over the surface of one of the trays, one seed in each of the 20 mask locations. Different computer-randomized lists were generated for each day to ensure that the birds could not predict the distribution of seeds on the tray.

\section{Test Apparatus}

The training and testing apparatus was a cubical wooden box, about $50 \mathrm{~cm}$ on a side. A window $(25 \mathrm{~cm}$ long $\times 12.4 \mathrm{~cm}$ wide $)$ cut in the side of the box was large enough to permit freedom of movement of the bird's head and neck without allowing it to climb out of the box. The window was covered by an opaque Plexiglas sliding door that could be opened by pulling a string attached to the top of the box.

During a trial, a gravel tray was placed on a Plexiglas stand in front of the window so that it was positioned at the same height as the bottom of the window. The timing of within-trial events was recorded in milliseconds by two timers. Infrared sensors mounted on the left and right sides of the door detected when the bird extended its head from the box. This event turned on both timers. A second array of infrared sensors was mounted on the left and right supports of the Plexiglas stand holding the gravel tray. This sensor array was positioned approximately $1 \mathrm{~cm}$ above the surface of the tray and detected pecks at the tray. The first timer, which was turned off when the bird first pecked the tray, thus recorded the duration from when the bird extended its head from the box to its first peck. The second timer, which was turned off manually by the experimenter at the end of the trial, thus recorded the duration of the entire trial.

\section{Procedure}

Pretraining - During the first 20 days of pretraining, birds were habituated to the apparatus, to eating the experimental grains from trays in the presence of the experimenter, to the removal and replacement of trays by the experimenter, and to the opening and shutting of the sliding Plexiglas door between trays. During an additional 20 days of pretraining, birds were conditioned to associate the sound of a loud tone signaling the end of the trial with the door's being promptly shut. They learned to withdraw into the box when the tone sounded. Over this pretraining period, birds were presented daily with 10 gray trays containing 10 wheat and 10 vetch seeds, and they were allowed to search for and consume all grains on each tray. The number of pecks required by each bird to collect all of the seed was recorded for each trial. While 3 of the birds (51, 53, and 93) followed the pretraining schedule described above, the 4th bird (71, added to the experiment after the first 3 birds had begun) was moved through each of the steps at an accelerated pace, completing all pretraining in a total of 20 days. 
Training - Over the first 14 days of training, the number of pecks required for each bird to remove, on average, half of the 20 grains from gray trays was determined. At the beginning of training, each trial was interrupted after the bird pecked 16 times at the tray, and the number of seeds taken was then calculated. The number of pecks allowed was then decreased over days until the number of pecks required to remove half of the grains was determined for each bird (the goal number ranged from 11 to 15 among the 4 birds).A second 14 days of training, now on cryptic trays containing 10 wheat and 10 vetch seeds, provided birds with search experience on the multicolored trays. Bird 71 completed this phase of training faster than the other 3 birds, receiving a total of only 12 days for both estimation of the goal number of pecks and experience with cryptic trays. At the end of this phase of training all 4 birds were completely familiar with the sequence of within-trial events as they would occur for the remainder of the experiment: A loud click cued the opening of the Plexiglas door at the beginning of the trial. The bird was allowed to deliver its goal number of pecks to the tray. A loud tone then sounded, immediately after which the door was shut. No more than 30 s elapsed between trials within a session.

An additional 35 days of training data were then collected. During this period the types of grains used were changed so that selection of the two grain types was equivalent when grains were presented on a tray in equal numbers. Pearled wheat (Triticum aestivum) and large common vetch seeds (seeds with diameters greater than $4.75 \mathrm{~mm}$ ) used throughout pretraining were also used during the first 20 days of this period. Because selection was biased strongly toward large vetch grains for 3 out of 4 birds, new stimuli were selected for the final 15 days of training. Red wheat was chosen to replace pearled wheat, and small common vetch (seeds with diameters less than $4.75 \mathrm{~mm}$ ) replaced the larger vetch. All 4 birds were given 5 days of training with 10 trials per day of 20 red wheat seeds on multicolored trays. For the final 10 days of training, all trays contained 10 red wheat seeds and 10 small common vetch seeds on either a multicolored or gray tray (there were 5 days with each background). These grains proved to be about equally difficult for all 4 birds to detect on the multicolored tray, as indicated by roughly equal selection of red wheat and vetch seeds (5.3 vetch seeds versus 4.7 red wheat seeds).

\section{Design}

The experimental design was a $2 \times 5$ within-subjects factorial. Each of the 4 birds was given one session per day, which consisted of 10 trials of a single tray background (multicolored or gray) and relative proportion $(0.0,0.2,0.5,0.8$, or 1.0 vetch).Five-day blocks of multicolored $(\mathrm{M})$ or gray $(\mathrm{G})$ tray sessions were run in counterbalanced order (MGGMGMMGMGGM).Each of the 10 Background $\times$ Proportion conditions was run for 6 days. Throughout the experiment the following were recorded for each trial: (a) the actual number of pecks delivered to the tray, (b) the time that the bird scanned the tray before its first response, (c) the total trial time from when the bird's head exited the box to its last response, and (d) the number of vetch and wheat grains remaining on the tray at the end of the trial.

\section{Method of Analysis}

Analysis of selection bias - If pigeons selected wheat and vetch grains randomly from trays, then the proportion of vetch taken should be equal to the proportion of vetch presented. To facilitate a comparison of our data with that of Bond (1983) and of Reid and Shettleworth (1992), we calculated a selection index based on the derived measure, $\alpha$, developed by Manly, Miller, and Cook (1972). The measure, $\alpha$, indicates the mean discrepancy between the proportion of a grain type on the tray and the proportion of that grain type taken. It is calculated as

$$
\alpha=\ln (A / a) \div \ln (B / b)
$$

where $A$ and $B$ are the number of grains of each type on the tray, and $a$ and $b$ are the number of grains of each type remaining after a trial. We obtained a value of $\alpha$ for each bird in each condition, using median values of $a$ and $b$. When the natural log is taken of the alpha score, a 0 indicates that grains were selected in the proportion presented.

We also calculated a selection index that summarizes the direction and magnitude of the selection bias across three relative-proportion conditions $(0.2,0.5$, and 0.8 vetch). When a value for $\alpha$ is obtained for each treatment in a range of proportions, it is approximately $\log$-linearly related to the proportion of $A$ grains. The selection index, the slope of the regression line of the natural log of $\alpha$ against the proportion of vetch, provides a summary measure of the direction and intensity of selection.

Analysis of speed and accuracy - We analyzed three measures to assess performance across experimental conditions: peck accuracy, first-peck reaction time, and rate of successive pecks. For all three measures we obtained a single estimate of central tendency of the 60 data points per experimental condition for each bird in order to arrive at one data point per condition per bird for the within-subjects analysis of variance (ANOVA).Peck accuracy reflects the difficulty that birds had in collecting grains from the rough gravel trays and was calculated for each trial as the ratio of the number of grains taken divided by the recorded number of pecks to the tray. We obtained an estimate of peck accuracy for each bird in each condition by taking the median of all trials in that condition.

First-peck reaction time represents the time required by the birds to visually scan a tray before pecking. We obtained an estimate of first-peck reaction time for each bird in each condition by taking the median of all trials, excluding those in which first-peck reaction times were greater than $4 \mathrm{~s}$. Trials on which first-peck reaction times were greater than $4 \mathrm{~s}$ were rare (only 1 trial out of 2, 400). First-peck reaction times greater than $4 \mathrm{~s}$ were therefore considered to be outliers, and we trimmed them from the distribution before obtaining the median score.

Successive-peck rate is the rate of pecks per second. It represents the time required by the bird to visually scan the tray, locate, peck at, and consume a grain for all pecks after the first. Successive-peck rate was calculated for each trial as the total number of successive pecks (number of actual pecks -1 ) divided by the total successive reaction time (total-trial reaction time - first-peck reaction time).We obtained an estimate of successive-peck rate for each bird in each condition by taking the median reaction time of the total set of trials, excluding those in which the first-peck reaction time was greater than $4 \mathrm{~s}$ and those in which the total trial reaction time was greater than $10 \mathrm{~s}$. These trials were rare $(14$ out of 2,400$)$ , were considered to be outliers, and were therefore trimmed from the distribution before we obtained the medians.

A repeated measures ANOVA (Background $x$ Proportion $x$ Bird) was performed on each of the three measures of speed and accuracy. Statistical tests with an alpha level less than .05 are reported as significant. Statistical tests with an alpha level between .05 and .10 are reported as nonsignificant, but the means are described as showing a trend. 


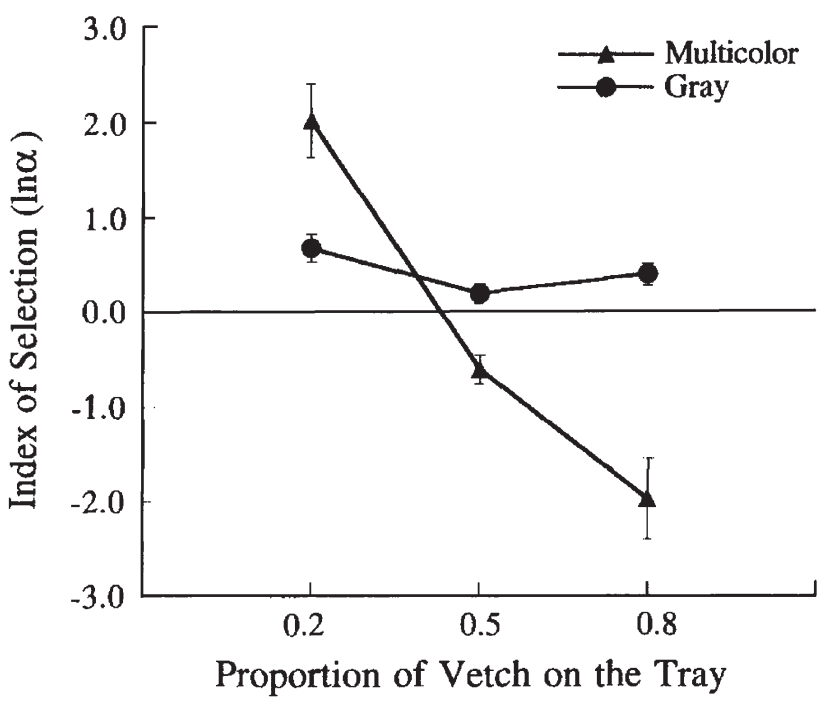

Figure 1. Pigeons overselected the most common grain on multicolored trays but did not show selection biases on gray trays. The natural log of Manly, Miller, and Cook's (1972) index of selection, $\alpha$, is shown here as a function of the proportion of vetch presented on the tray. Standard error bars indicate variance between subjects.

\section{Results}

\section{Analysis of Selection Bias}

Grain selection biases occurred on multicolored trays but not on gray trays. shows the natural log of Manly et al.'s (1972) index of selection, $\alpha$, as a function of the proportion of vetch presented on multicolored and gray trays containing both types of grain. We used a Background $\times$ Proportion $\times$ Bird ANOVA with weighted orthogonal polynomials to test for a selection bias across the $0.2,0.5$, and 0.8 vetch proportion conditions. Because our selection index is the slope of the regression of $\ln \alpha$ on relative proportion, the effects of concern in our ANOVA were only those that included interactions with the first, or linear, component of the proportion factor. The Background $\times$ Proportion interaction was significant: The selection indices differed significantly between multicolored and gray conditions $(-6.67$ vs. -0.4$), F(1,3)=$ 17.43. This interaction is accounted for by the presence of a significant linear effect of proportion for multicolored trays, $F(1,3)=11.55$, and an absence of a linear effect of proportion for gray trays, $F(1,3)=1.18$.

Wheat and vetch grains were selected in the same proportion presented in the multicolored 0.5 vetch condition. An ANOVA performed on the natural log alpha scores revealed that grain selection on the multicolored trays in the 0.5 vetch condition did not differ from random $(\ln \alpha$ did not differ from $0), F(1,3)=3.83$.

\section{Analysis of Speed and Accuracy}

Pecks were more accurate to grains when they were conspicuous than when they were cryptic and more accurate to vetch than to wheat on both multicolored and gray trays (see Figure 2). A Background $\times$ Proportion $\times$ Bird ANOVA revealed that pecks were significantly more accurate when grains were presented on a gray, rather than a multicolored, tray, $F(1,3)=12.2$. This ANOVA also revealed that pecks were more accurate to vetch than to wheat on multicolored and gray trays: Peck accuracy differed significantly between proportions, $F(4,12)=8.0$, and the interaction between background and proportion was not significant, $F(4$, $12)=1.0$. The fact that pecks to vetch were significantly more accurate than pecks to wheat on both multicolored and gray trays suggests that wheat grains were more difficult to handle than vetch grains. If peck accuracy had varied as a function of grain type only on multicolored trays, then a difference in peck accuracy could be argued to reflect differences in both detectability and handling. Because pecks were more accurate to vetch than to wheat on both multicolored and gray trays, we conclude that differences in handling, rather than differences in detectability of prey, account for differences in peck accuracy.

First-peck reaction times did not differ between experimental conditions. A Background $\times$ Proportion $\times$ Bird ANOVA revealed no significant differences between firstpeck reaction times to multicolored and gray trays, $F(1,3)=$ 1.2 , ns, or between proportions, $F(1,3)=0.6$, ns. The Background $\times$ Proportion interaction was also nonsignificant, $F(4$, 12) $=1.4$.

Successive-peck rates, however, were faster on gray trays than on multicolored trays, and successive-peck rates were faster when only one type of grain was on a multicolored tray than when two types were present (see Figure 2). A Background $\times$ Proportion $\times$ Bird ANOVA revealed that the pigeons pecked at a significantly higher rate at grain on gray trays than at grain on multicolored trays, $F(1,3)=851.0$, which indicates that grains were more conspicuous on gray trays than on multicolored trays. The Background $\times$ Proportion interaction was also significant, $F(4,12)=5.7$, because successive-peck rate differed significantly between proportions on multicolored trays, $F(4,12)=5.9$, but not on gray trays, $F(4,12)=1.13$. Because there was no significant difference between successive-peck rates for the 0.0 and 1.0 vetch conditions on multicolored trays, $F(1,3)=2.58$, data from these conditions were combined for comparison with successive-peck rate in the 0.5 vetch condition. Successive-peck rate was faster in the homogeneous conditions (all wheat or all vetch) than in the heterogeneous 0.5 vetch condition, $F(1$, 3) $=13.7$.

\section{Discussion}

The results of Experiment 1 are fully consistent with those of Bond (1983). Evidence of search images included overselection of the most common grain on the tray and improvement in speed of grain collection when one grain type was repeatedly encountered. Pigeons overselected the most common grain on multicolored trays containing two types of grain (vetch was overselected on 0.8 vetch trays, and wheat was overselected on 0.2 vetch trays). They also collected grain 

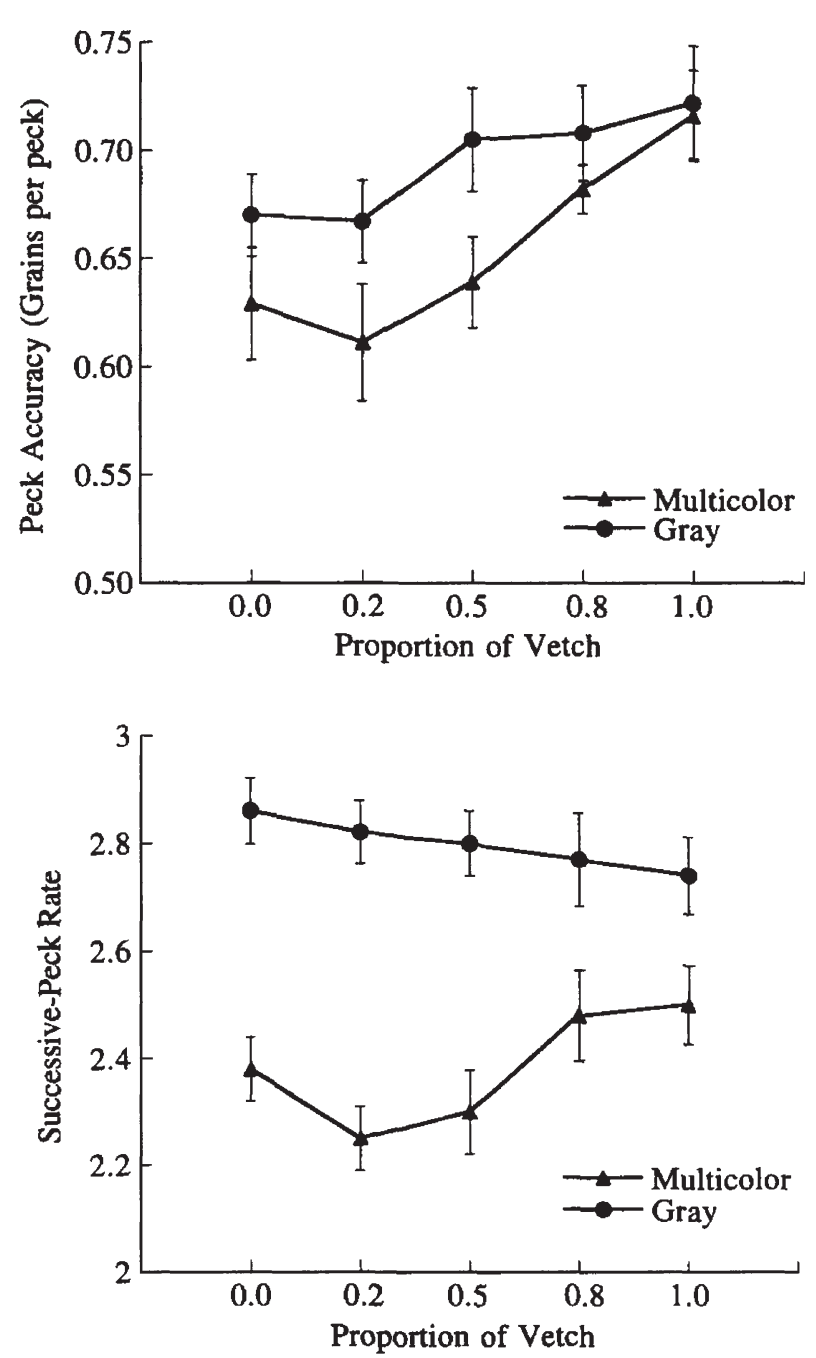

Figure 2. Peck accuracy and successive-peck rate on multicolored and gray trays are shown as a function of proportion of vetch presented on the tray

faster in multicolored-tray conditions where a single type of grain was repeatedly encountered (in the homogeneous, allwheat and all-vetch conditions) than in the heterogeneous 0.5 vetch condition.

The results of Experiment 1 cannot be accounted for by the preference hypothesis. If overselection occurred as a result of a change in preference for a frequently encountered grain type, we would have expected such a change to occur whether grains were cryptic or conspicuous. Overselection occurred only when the search was for cryptic grains. The fact that the search-image effects appeared only when perceptual load was high supports a model in which search images are viewed as selective attention to visual features of a particular prey.

The results of Experiment 1 also cannot be accounted for by Guilford and Dawkins's (1987) stare-duration hypothesis, because the two grain types presented were equally cryptic: Grains were selected randomly from the 0.5 vetch multicolored trays, and successive-peck rate did not differ for the wheat and vetch grains on multicolored trays.
Experiment 2

Experiment 1 demonstrated search-image effects when prey were cryptic but not when they were conspicuous (as did Bond, 1983; Bond \& Riley, 1991; Reid \& Shettleworth, 1992). This research indicates that prey crypticity is necessary for the activation of a search image, for the effects of an activated search image to be revealed, or both. We conducted Experiment 2 to answer the following two questions: (a) Is prey crypticity necessary for the activation of a search image? and (b) Is prey crypticity necessary for a search image to affect search performance? To determine which role prey crypticity plays in search-image effects, we designed an experiment in which repeated encounters with a single type of grain occurred on one tray (the "setting" tray) and the effect of those repeated encounters on grain selection was measured on a separate tray (the "probe" tray). Our experimental design was based on those of Dawkins (1971a, 1971b) .

In Experiment 2, pigeons were fed from setting trays containing only wheat or only vetch grains and from occasional probe trays containing equal numbers of wheat and vetch grains. Performance on probe trays presented within a series of vetch or wheat setting trays was compared with performance on probe trays presented within a series of "nonsetting" trays. Nonsetting trays, like probe trays, contained equal numbers of wheat and vetch grains. No consistent search image should be activated as a result of searching for grains on nonsetting trays, so probes presented in a series of nonsetting trays serve as a control. On the basis of Experiment 1 we expected the proportion of vetch selected to be highest on probe trays presented within a series of vetch setting trays, lower on probe trays presented within a series of nonsetting trays, and lowest on probe trays presented within a series of wheat setting trays.

By independently manipulating prey crypticity on setting and probe trays, we could examine whether prey crypticity was necessary for activation of a search image, or for an activated search image to affect search performance, or both. Daily session types were defined by tray background for probe trays and setting trays. The four types of sessions were multicolored-setting-multicolored-probe (MM) sessions, multicolored-setting-gray-probe (MG) sessions, graysetting-multicolored-probe (GM) sessions, and gray-settinggray-probe (GG) sessions.

To determine whether crypticity was necessary for the activation of a search image, we compared grain selection on probes in the MM and GM conditions. If a search image was activated on a setting tray, then we would expect it to be carried over to a subsequent multicolored probe. If the results showed that a search image could only be activated when the prey encountered was cryptic (in the MM, but not the GM, sessions), we would conclude that selective attention is focused on visual features of a prey only when the prey must be discriminated from a cryptic background. Alternatively, if the results showed that a search image could be activated by repeated encounters with either a conspicuous or cryptic prey (in the MM and GM sessions), we would conclude that 
selective attention to the visual features of a prey does not require discrimination.

If selective attention to visual features of a particular prey underlies search-image effects, then prey crypticity should be necessary for us to detect evidence of an active search image. When perceptual load is very low, the pigeons' ability to detect both grain types should be at a ceiling, and the presence of a perceptual bias for one grain type should not be demonstrable. To determine whether prey crypticity is necessary for an active search image to influence search performance, we compared probe performance in the MM and MG sessions. Search images should be activated on multicolored wheat and vetch setting trays and should be evident on multicolored probes (MM session) but not on gray probes (MG session).

It may be that prey crypticity is necessary both for activation of a search image and for detection of evidence of an active search image. If this is the case, then search-image effects should be evident only on probes in the MM condition.

\section{Method}

Subjects and apparatus (including the colony lighting regimen, trays, stimulus grains, stimulus placement, and apparatus) were the same for this experiment as Experiment 1, with the exception that Bird 51, which died, was replaced by Bird 30. Bird 30 received similar, though less elaborate, pretraining.

\section{Procedure}

All 4 birds received 40 days of training prior to final data acquisition. During this period the goal number of pecks was set for each of the 4 birds so that 8 out of 20 grains were removed from each tray. We changed the goal number of pecks from 10 to 8 to increase the reliability and robustness of the search-image effect. When a bird collects grains on a probe trial containing 10 wheat and 10 vetch grains, it is more likely to select 8 grains matching an established search image than it is to select all 10 grains before encountering the opposite grain type. Because encounters with an opposite grain type might disrupt the search image, birds collecting only 8 grains should be less likely to be disrupted than birds collecting 10 grains. All within-trial events were the same as for Experiment 1.

\section{Design}

Throughout the experiment the birds participated in one session each day. Each session consisted of seven setting trials and three probe trials. Positions of the three probe trials within the session were randomly determined each day with the constraints that the first three trials consist of setting trays and that at least one setting tray be presented between the first and second probe trays and the second and third probe trays.

The experiment was conducted in two phases: experimental and control. In the experimental phase (Phase 1) setting trays contained either wheat or vetch grains. Each of the four session types (MM, MG, GM, GG) occurred in a block of 8 days twice in Phase 1. We randomized the order of session-type blocks separately for the 4 birds to determine the order of presentation for the first four blocks. This order was then reversed for the second four blocks. Vetch and wheat setting days were counterbalanced in an ABBA-
BAAB sequence within each 8-day session-type block. Each Session Type $\times$ Setting Grain condition occurred on 8 days of Phase 1 , thus providing 56 setting-tray data points and 24 probe-tray data points per condition per bird.

In the control phase (Phase 2) all trays contained equal numbers of wheat and vetch grains. Thus, probe and nonsetting trials did not differ in any respect in the MM and GG sessions. Nonsetting trials differed from probe trials in tray background only in the MG and GM sessions. The four session types (MM, GM, MG, GG) occurred in two 4-day blocks. We randomized the order of the four session types separately for each of the 4 birds to determine the order of the first four session-type blocks, and this order was reversed for the second four session-type blocks. Each session-type condition occurred on 8 days each, thus providing 56 setting-tray data points and 24 probe-tray data points per condition per bird.

\section{Method of Analysis}

A series of within-subjects ANOVAs examined probe trial performance. Peck accuracy, first-peck reaction time, and rate of successive pecks were calculated as described in the "Method of Analysis" section of Experiment 1. We analyzed grain selection on probe trials by obtaining the median number of vetch and wheat grains taken for each bird on probe trays appearing in the wheat setting, vetch setting, and nonsetting tray conditions. Manly et al.'s (1972) index of selection was calculated for probes appearing in each setting-tray condition.

\section{Results}

Search-image effects were evident in the analysis of grain selection on probe trays: Pigeons demonstrated selection biases when probe trays were multicolored (in the MM and GM conditions) but not when probe trays were gray (in the MG and GG conditions). Figure 3 shows the natural log of Manly et al.'s (1972) alpha score as a function of setting-tray condition for all four session types. A Setting-Tray Type $\times$ Setting Background $\times$ Probe Background $\times$ Bird ANOVA performed on the ln $\alpha$ scores revealed no significant main effect of setting background and no significant interactions of setting background with any other factor. Because there was not a significant effect of setting background, data from the MM and GM conditions were combined and data from the MG and GG conditions were combined for further analysis.

Grain selection was influenced by whether probe trays were multicolored or gray and by whether the probes appeared in a wheat setting, nonsetting, or vetch setting session. A Setting-Tray Type $\times$ Probe Background $\times$ Bird ANOVA, which used weighted orthogonal polynomials, revealed that the linear trend of $\ln \alpha$ across setting-tray type (vetch, wheat, and nonsetting trays) interacted significantly with probe background, $F(1,3)=26.36$. This interaction was the result of a significant linear trend for setting-tray type for multicolored probes, $F(1,3)=21.36$, and the absence of a significant linear trend for setting-tray type for gray probes, $F(1$, $3)=2.86$. Search images activated on either a gray or multicolored setting tray biased grain selection on multicolored probe trays, but not on gray probe trays. 

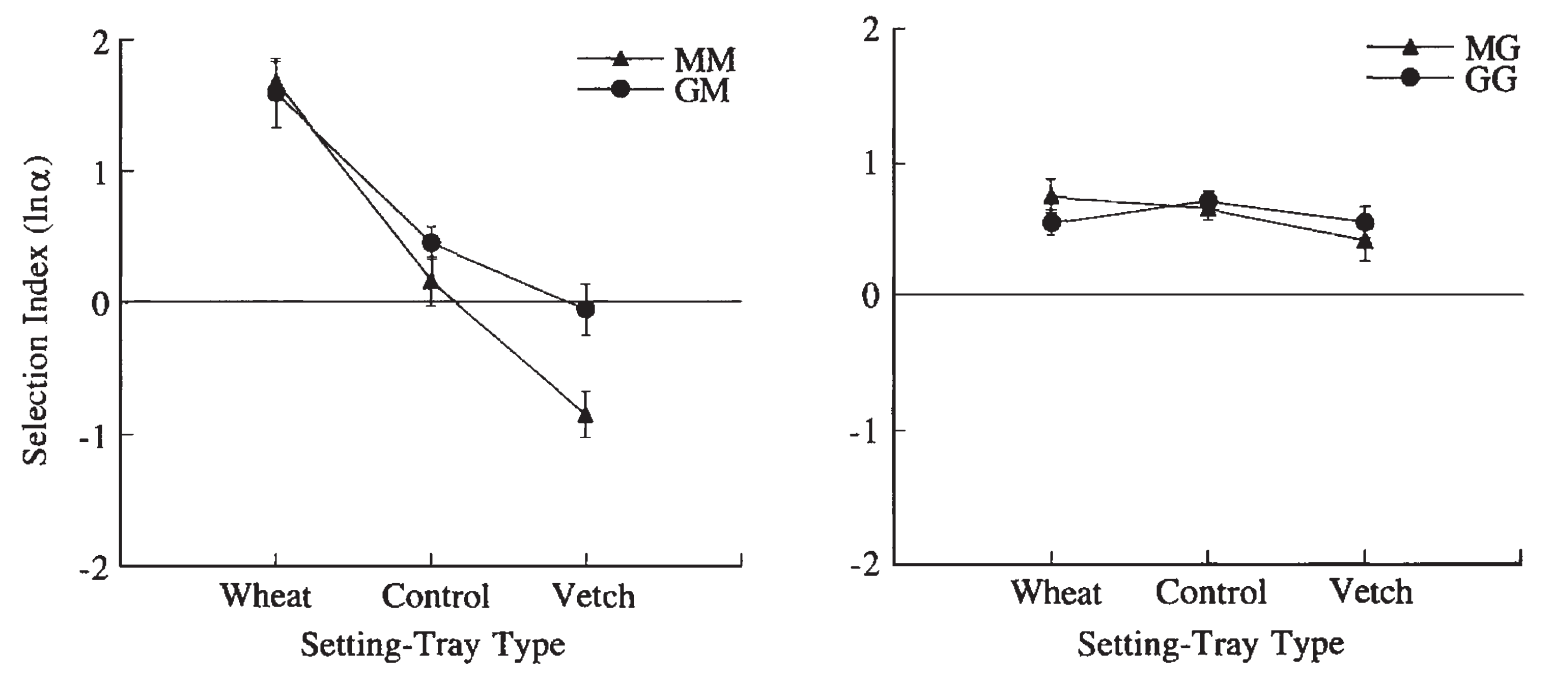

Figure 3. Pigeons were biased to select the type of grain encountered on setting trays when probes were multicolored but not when they were gray. Search images were activated on both multicolored and gray trays. MM = multicolored-setting-multicolored probe session; $\mathrm{GM}$ = gray-setting-multicolored-probe session; $\mathrm{MG}$ = multicolored-setting-gray-probe session; GG = gray-setting-gray-probe session .

First-peck reaction times were faster and peck accuracy showed a trend toward being higher on experimental probes (those in wheat or vetch setting sessions) than control probes (those in nonsetting sessions). Setting-Tray Type $\times$ Setting Background $\times$ Probe Background $\times$ Bird ANOVAs were performed for all three measures of speed and accuracy. The results revealed no significant main effect of setting background. Therefore, the MM and GM conditions were combined and the MG and GG conditions were combined for Setting-Tray Type $\times$ Probe Background $\times$ Bird ANOVAs. These ANOVAs revealed a significant main effect of settingtray type for peck accuracy, $F(2,6)=7.00$, and for first-peck reaction time, $F(2,6)=9.05$, but not for successive-peck rate, $F(2,6)=0.86$.

Vetch and wheat probe conditions were combined into one condition (experimental probes) and compared with the nonsetting condition (control probes) so that we could discover the source of the significant main effect of setting-tray type for peck accuracy and first-peck reaction time. The collapsing of the vetch and wheat setting probe conditions into the experimental probe condition is justified by the fact that probes in vetch and wheat sessions did not differ in peck accuracy, $F(1,3)=1.79$, or first-peck reaction time, $F(1,3)=3.33$.

First-peck reaction time was faster to probe trays in experimental sessions than in control sessions (see Figure 4). A Probe Type $\times$ Probe Background $\times$ Bird ANOVA revealed significantly faster first-peck reaction times to experimental probes than to control probes, $F(1,3)=32.81$. The ANOVA did not reveal a significant difference between experimental probe and control probe peck accuracy, although the means showed a trend toward higher peck accuracy for experimental probes than for control probes, $F(1,3)=9.00$. Probe type did not interact significantly with probe background for either peck accuracy, $F(1,3)=3.60$, or first-peck reaction time,
$F(1,3)=2.48$. The significantly faster first-peck reaction time and the trend toward higher peck accuracy for probe trays within wheat or vetch setting-tray series, relative to probe trays within nonsetting-tray series, reflect the transfer of search images from setting to probe trays.

\section{Discussion}

The analysis of grain selection biases in Experiment 2 demonstrated that search images can be activated on either multicolored or gray trays but that they are only evident when search is for grain on multicolored trays. Search-image effects were evident in the MM and the GM conditions. The fact that search images were activated after encounters with

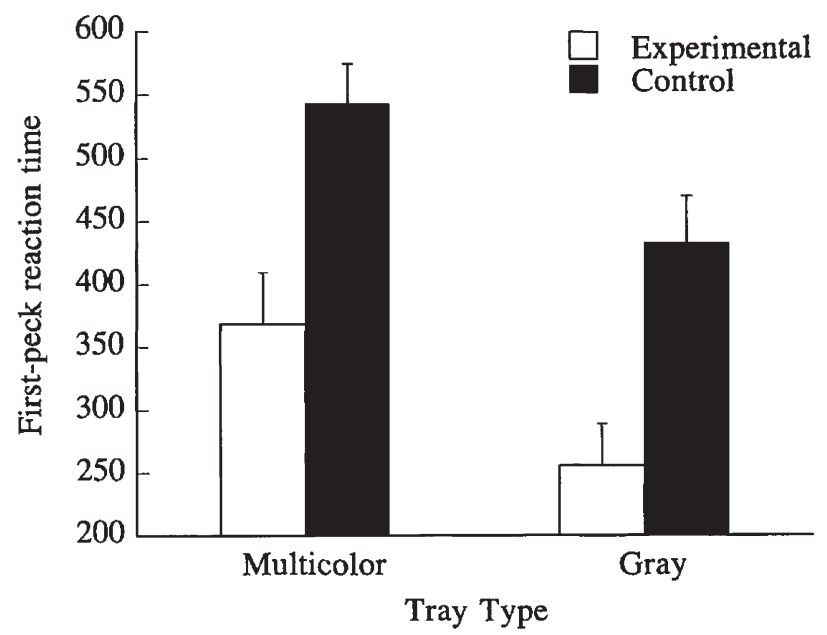

Figure 4. First-peck reaction times were faster on both multicolored and gray probe trays following wheat or vetch setting trays than following nonsetting trays 
either cryptic or conspicuous prey provides evidence that selective attention can be focused on the visual features of a prey as a result of mere exposure to that prey. Focusing of selective attention does not require that the pigeon discriminate the prey from a background with which it shares common visual features. Search-image effects were evident in the MM session but not in the MG session. As predicted, an active search image did influence search on multicolored probes but not on gray probes, where discriminability of both prey types was at a ceiling.

Comparisons of probe trial speed or accuracy did not provide strong evidence of search-image effects. Successive-peck rate and peck accuracy did not differ significantly between experimental probes (in wheat or vetch setting sessions) and control probes (in nonsetting sessions). Firstpeck reaction times were faster to experimental probes than to control probes for all session types. This finding suggests that some effects of an activated search image were evident very early during the trial on both multicolored and gray probes. Selection bias, successive-peck rate, and peck accuracy reflect search performance over the entire probe trial. First-peck reaction times reflect search performance for only the first grain selection. If a search image influenced search performance for grains on gray trays at all, it would be most likely to affect the first few selections of grain (before the conspicuous, alternative grain type was encountered).

As noted in the introduction to this experiment, our design was based on those of Dawkins (1971a, 1971b). Dawkins (1971b) concluded from her experimental results that crypticity might be necessary for predators' attention to be focused on visual features of a prey. Dawkins's conclusion conflicts with ours. Dawkins presented orange and green rice grains to chicks on orange and green gravel trays. The orange grains were cryptic on orange trays but conspicuous on green trays. Likewise, green grains were cryptic on green trays but conspicuous on orange trays. After successive encounters with one type of grain during an initial stage of each experimental trial, the chick was exposed to both grain types. Dawkins found a selection bias for cryptic orange grains (presented with a conspicuous green grain at test) only after chicks had initially encountered cryptic orange grains. When the chicks had initially encountered conspicuous orange grains, they selected a conspicuous green grain when both grain types were presented.

Dawkins (1971b) concluded from these results that the chicks focused attention on visual features of the orange grain following frequent encounters with cryptic orange grains, but not after frequent encounters with conspicuous orange grains. An alternative interpretation of her results is that search images were activated after encounters with either cryptic or conspicuous orange grains but that the search image activated by conspicuous orange grain encounters did not cause such a strong perceptual bias that the birds subsequently failed to detect conspicuous grains of another color. Dawkins presented one cryptic and one conspicuous grain at test. Our experimental preparation differs from that of Dawkins because we presented two equally cryptic grains on probe trays. The presentation of two equally cryptic grains on our probe tests appears to have provided a more sensitive test of the presence of a search image after encounters with a conspicuous grain than did Dawkins's test. Thus, we were able to demonstrate that search images can be activated when initially encountered grains are conspicuous.

\section{Experiment 3}

Experiment 3 was conducted for the purpose of testing whether a delay or an interference event interpolated between successive discoveries of a type of grain would deactivate an established search image. Bond's (1983) attention threshold model suggests that pigeons alternate between a general search mode (when they have no perceptual bias) and a specific search mode (when they have a search image). Birds are presumed to be in specific search mode after repeated encounters with one prey type, to switch into a general search mode when that prey type is locally depleted, and to move into a specific search mode again after encountering another prey type. Thus Bond's (1983) model suggests that an activated search image can be disrupted when prey matching the image are not encountered over a period of time. Previous experiments have demonstrated that visual predators can rapidly exchange one search image for another when the prey type that they encounter frequently changes (Bond, 1983; Bond \& Riley, 1991; Pietrewicz \& Kamil, 1979, 1981; Reid \& Shettleworth, 1992) , but it has not been shown that a brief time delay between successive encounters with a prey type can result in search-image decay.

In Experiment 3 birds were fed from setting trays containing either wheat or vetch grains and from occasional probe trays containing equal numbers of wheat and vetch grains. Setting and probe trays were all multicolored. Because the search image is activated on the setting tray and tested on a separate probe tray, we were able to interpolate either a 30-s delay between setting and probe, a 3-min delay between setting and probe, or a 3-min delay plus exposure to an empty multicolored tray between setting and probe. Measures of grain selection on probe trays following wheat and vetch setting trays were compared with measures of grain selection on probe trays following nonsetting (50\% vetch) trays, as in Experiment 2. Search-image effects would be evident if vetch was overselected on probe trays within a series of vetch setting trays, if vetch was selected in the same proportion as it was presented in a series of nonsetting trays, and if vetch was underselected on probe trays within a series of wheat setting trays.

If search images are evident when there is a 30-s delay between setting and probe, but not when there is a 3-min delay between setting and probe, then this result would support the hypothesis that search images decay over time. Exposure to the empty tray in the delay-plus-interference condition was intended to allow the birds time to actively search without encountering the prey type matching their search image. If search images are evident when there is a 30-s or a 3-min delay between setting and probe but not when there is a 3- 

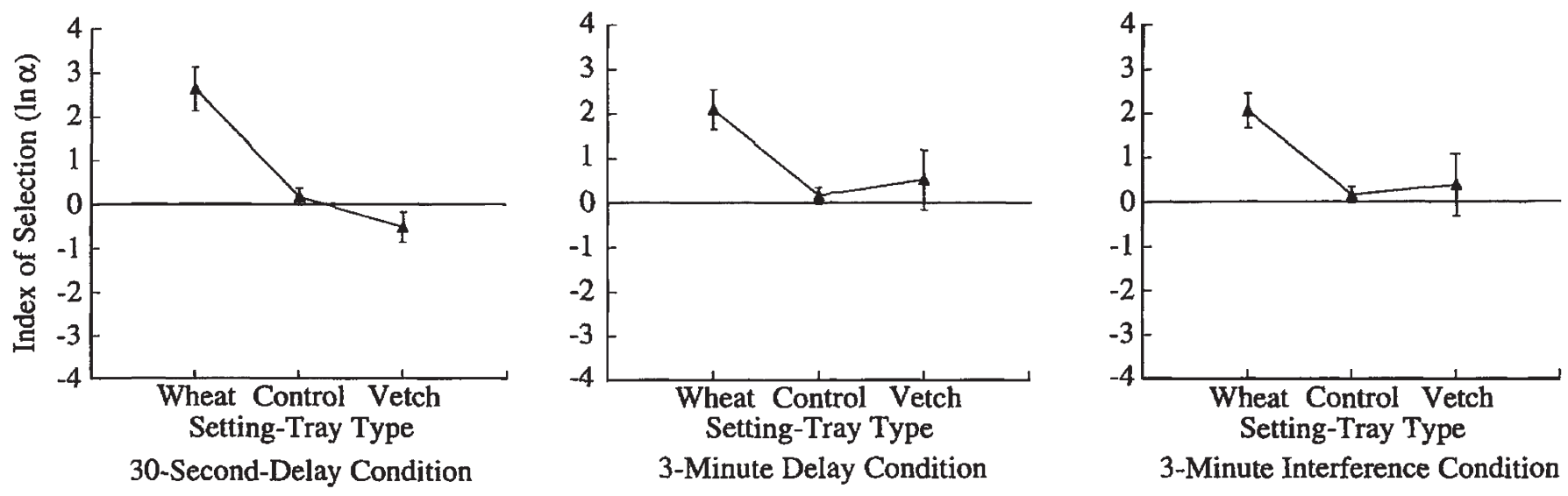

Figure 5. Selection biases were evident on probe trials that followed setting trials by a 30-s delay but not on probe trials that followed setting trials by a 3-min delay or by a 3-min delay including search of an empty multicolored tray

min delay plus exposure to an empty multicolored tray between setting and probe, then this would suggest that time alone cannot deactivate a search image, but rather that active search without prey encounters is necessary for deactivation of a search image.

\section{Method}

\section{Subjects}

Subjects and apparatus, including the colony lighting regimen, trays, stimulus grains, stimulus positioning, and test apparatus, were the same for this experiment as for Experiment 1.

\section{Procedure}

No training was given prior to the beginning of Experiment 3. The goal number of pecks remained set for each of the 4 birds so that 8 out of 20 grains were removed from each tray. Within-trial events were the same as in the first and second experiments, with the exception of the different delays between setting and probe trials.

\section{Design}

The design of this experiment was a $3 \times 3 \times 4$ factorial: SettingTray Type $\times$ Delay Condition $\times$ Bird. Each bird was given two sessions of 10 trials per day. Each session consisted of seven setting trials with either 20 wheat or 20 vetch grains, and three probe trials with 10 wheat and 10 vetch grains. Three types of delay conditions were included in the experiment. In the 30-s delay condition, probe trials were presented $30 \mathrm{~s}$ after the bird finished the preceding setting trial. In the 3-min delay condition, probe trials were presented $3 \mathrm{~min}$ after the bird finished the preceding setting trial. In the 3-min interference condition (a) an empty cryptic tray was presented $2 \mathrm{~min}$ after the bird had finished the preceding setting trial, (b) the bird was exposed to the empty cryptic tray for a period of $30 \mathrm{~s}$, and (c) the probe trial was presented $30 \mathrm{~s}$ after the empty tray had been taken away from the bird.

Each probe type was presented once in each 10-trial session, and the order in which the three probe types occurred was randomized for each session for each bird. Positions of the three probe trays in each session were randomly determined with the constraints that the first two trials consist of setting trays and that at least one setting tray be presented between the first and second and between the second and third probe trials. Setting grain session types occurred in blocks of five sessions, and the order of the blocks of sessions was counterbalanced in an ABBABAAB fashion. Over the 40 sessions of the experiment there were 20 data points per each of the three probe types for wheat setting and 20 data points per vetch setting sessions.

The control probe trial data are taken from the MM condition in Phase 2 of Experiment 2. Control probes were all presented $30 \mathrm{~s}$ after the preceding setting tray.

\section{Method of Analysis}

Peck accuracy, first-peck reaction time, and rate of successive pecks were calculated as described in the "Method of Analysis" section of Experiment 1. We analyzed grain selection on probe trials by obtaining the median number of vetch and wheat grains taken by each bird on probe trays appearing within the wheat setting, vetch setting, and nonsetting tray conditions for each of the delay conditions. The proportion of vetch taken, relative to the total number of vetch and wheat grains taken, and Manly et al.'s (1972) index of selection were calculated for probes appearing in each setting-tray condition for each delay condition.

\section{Results}

\section{Selection Bias}

Pigeons reliably selected more vetch following vetch setting probes than following wheat setting probes in the 30-s delay condition, but not in the 3-min delay or the 3-min interference conditions (see Figure 5). The Setting-Tray Type $\times$ Delay Condition $\times$ Bird ANOVA conducted on the natural log of $\alpha$ used weighted orthogonal polynomials for contrasts involving setting-tray type. The only effects of concern were those that included interactions with the first, or linear, component of the setting-tray type factor. In this ANOVA setting-tray type and delay condition did not interact significantly, although the means showed a trend, $F(2,6)=3.61$. Analyses of the linear trend of ln $\alpha$ for setting-tray type in each delay con- 
dition did not reveal a significant linear trend in the 30 -s delay condition, $F(1,3)=7.76$, although the means did show a trend toward linearity. Probe type was not significant for the 3-min delay, $F(1,3)=2.82$, or the 3 -min interference, $F(1,3)=$ 4.97, conditions.

Each pigeon reliably selected more vetch following vetch setting probes than following wheat setting probes in the 30 s delay condition. The fact that the effect of setting-tray type did not reach significance for the 30-s delay condition was of some concern, because the same test did reach significance in Experiment 2. Because each bird showed the predicted selection bias in the 30-s delay condition in this experiment, we tested whether the predicted bias occurred reliably across blocks of days for each of the 4 birds. The median number of vetch and wheat grains remaining on probe trays was determined for five 4-day blocks for the wheat and vetch setting-tray conditions for each bird. The natural log of Manly et al.'s (1972) alpha score was calculated for each of the five blocks, and the scores for wheat and vetch setting-tray sessions were compared in an ANOVA (this procedure is equivalent to testing for a linear trend across setting-tray type for each bird). There was a significant difference in $\ln \alpha$ scores for probes in wheat versus vetch setting-tray conditions for each of the 4 birds, $F s(1,4)=64.71,11.99,33.52$, and 25.02. The fact that setting-tray type did not reach significance for the 30$\mathrm{s}$ delay condition in the Setting-Tray Type $\times$ Bird ANOVA reported above can therefore be interpreted as the result of great variance between birds in the current experiment, rather than being due to a weak or unreliable effect of wheat or vetch grain exposure on probe-trial grain selection in the 30-s delay condition.

\section{Speed and Accuracy}

Speed and accuracy of grain collection on probe trays did not differ as a function of setting-tray type or delay condition. Setting-Tray Type $\times$ Delay Condition $\times$ Bird ANOVAs were performed for all three measures of speed and accuracy. Vetch and wheat probe trials did not differ in peck accuracy, $F(1,3)=0.00$, in first-peck reaction time, $F(1,3)$ $=1.30$, or in successive-peck rate, $F(1,3)=0.56$. Vetch and wheat probe conditions were therefore combined into one condition (experimental probes), and experimental probe performance was compared with control probe performance in Probe Type $\times$ Delay Condition $\times$ Bird ANOVAs. Experimental probes did not differ from control probes in peck accuracy (.602 vs. .611), $F(1,3)=0.22$, first-peck reaction time (422.5 ms vs. $547.1 \mathrm{~ms}), F(1,3)=1.22$, or successive-peck rate (2.03 vs. 1.98$), F(1,3)=0.42$. Probe types (30-s, 3-min delay, 3 -min interference) did not differ in peck accuracy (.604 vs. .606 vs. .610), $F(2,6)=0.11$, first-peck reaction time $(490.8 \mathrm{~ms}$ vs. $492.6 \mathrm{~ms}$ vs. $470.9 \mathrm{~ms}), F(2,6)=1.36$, or successive-peck rate $(2.06$ vs. 1.94 vs. 2.03$), F(2,6)=1.05$.

\section{Discussion}

The presence of a significant selection bias for each of the pigeons over blocks of experimental days in the 30-s delay condition, but not in either the 3-min delay condition or the 3- min interference condition, demonstrates that time delay alone is sufficient for deactivation of a search image. This result provides support for Bond's (1983) dynamic model of changes in attention while foraging. Evidence that a brief time delay ( $3 \mathrm{~min}$ ) between successive encounters with a prey type can result in search-image decay lends support to a selective attention account of search images, as opposed to a discrimination learning account.

\section{General Discussion}

The literature review presented in the introduction suggests that a search image is a perceptual expectancy set by repeated encounters with a particular type of prey. Evidence of search images in Experiment 1 included overselection of the most common type of grain on multicolored trays and improvement in speed of grain collection when one grain type was repeatedly encountered (on all-wheat and all-vetch trays). The controls included in the design of Experiment 1 allow us to discount changes in preference or changes in stare duration as explanations of our results, thus strengthening our conclusion that search-image effects are the result of selective attention to visual features of a particular prey type.

The literature review also indicates that search-image effects are evident only when prey are cryptic. The results of Experiment 2 allow us to add that prey crypticity is necessary for an activated search image to affect performance but that prey crypticity is not necessary for activation of a search image. Mere exposure to a prey type can activate a search image: Focusing of selective attention to visual features of a particular prey does not depend on the predator's having to discriminate between features of prey and features of the background on which the prey is cryptic.

Our conclusion that prey crypticity is necessary for an activated search image to affect performance is based on our grain selection bias results. This conclusion is modified little by the fact that first-peck reaction times were faster on multicolored and gray probes following wheat or vetch setting trays than on probes following nonsetting trays. There was no evidence of search-image effects on gray probe trays for the measures that reflect search performance over the entire probe tray (selection bias, successive-peck rate, and peck accuracy). Although an activated search image may affect perception very early on a gray probe tray, encounters with conspicuous alternative prey are also likely to occur early on gray probes, thus weakening the perceptual bias. A search image, therefore, does not affect search performance on any but the first few responses when prey are conspicuous.

Experiment 3 demonstrated that a 3-min time delay between setting and probe trays was sufficient for deactivation of a search image. This result provides support for Bond's (1983) dynamic model of changes in attention while foraging and lends support to a selective attention account of search images, as opposed to a discrimination learning account.

Research that could further develop a model in which search images are viewed as selective attention could at- 
tempt to determine to which visual features of a prey the predator attends. Do birds attend to many features of a particular prey or only a few? Do the features to which the bird attends depend on the context in which the prey are presented? The results of Experiment 2 suggest that the pigeons were attending to those visual features of grains after encountering them on gray setting trays that allowed them to detect the grain more easily when subsequently presented on multicolored probe trays. This may indicate a tendency to fix attention on simple features, such as color or shape, that are invariant across backgrounds. On the other hand, these birds had extensive prior training with the stimuli on both backgrounds and may have converged on the set of stimulus features they attended to based on this prior experience. In another preparation, it would seem possible that the visual features attended to after encounters with a prey in one context might not be the same as those attended to after encounters with the same prey in a different context, in which case search performance in the second context might not be as influenced by prior experience with the prey.

\section{References}

Blough, P. M. (1989). Attentional priming and search images in pigeons. Journal of Experimental Psychology: Animal Behavior Processes, 15, 211-223.

Blough, P. M. (1991). Selective attention and search images in pigeons. Journal of Experimental Psychology: Animal Behavior Processes, , 17(3) , 292-298.

Blough, P. M. (1992). Detectability and choice during visual search: Joint effects of sequential priming and discriminability. Animal Learning \& Behavior, 20, 293-300.

Bond, A. B. (1983). Visual search and selection of natural stimuli in the pigeon: The attention threshold hypothesis. Journal of Experimental Psychology: Animal Behavior Processes, 9, 292-306.

Bond, A. B., \& Riley, D. A. (1991). Searching image in the pigeon: A test of three hypothetical mechanisms. Ethology, 87, 203-224.

Dawkins, M. (1971a). Perceptual changes in chicks: Another look at the "search image" concept. Animal Behaviour, 19, 566-574.

Dawkins, M. (1971b). Shifts of "attention" in chicks during feeding. Animal Behaviour, 19, 575-582.

Endler, J. A. (1984). Progressive background matching in moths, and a quantitative measure of crypsis. Biological Journal of the Linnaen Society, 22, 187-231.
Endler, J. A. (1991). Interactions between predators and prey. In J. R. Krebs, \& N. B. Davies (Eds.) , Behavioral ecology (pp. 169196). New York: Blackwell Scientific.

Eriksen, C. W., \& Yeh, Y. Y. (1985). Allocation of attention in the visual field. Journal of Experimental Psychology: Human Perception \& Performance, 11, 583-597.

Fullick, T. G., \& Greenwood, J. J. D. (1979). Frequency dependent food selection in relation to two models. American Naturalist, $113,762-765$.

Guilford, T., \& Dawkins, M. S. (1987). Search images not proven: A reappraisal of recent evidence. Animal Behavior, 35, 1838-1845.

Harvey, P. H., Birley, N., \& Blackstock, T. H. (1975). The effect of experience on the selective behaviour of song thrushes feeding on artificial populations of Cepaea (Held). Genetica, 45, 211-216.

Lawrence, E. S. (1985a). Evidence for search image in blackbirds. (Turdus merula L.) : Short-term learning. Animal Behaviour, 33, 929-937.

Lawrence, E. S. (1985b). Evidence for search image in blackbirds (Turdus merula L.) : Long-term learning. Animal Behaviour, 33, 1301-1309.

Manly, B. F. J., Miller, P., \& Cook, L. M. (1972). Analysis of a selective predation experiment. American Naturalist, 106, 719-736.

Pietrewicz, A. T., \& Kamil, A. C. (1979). Search image formation in the blue jay (Cyanocitta cristata). Science, 22, 1332-1333.

Pietrewicz, A. T., \& Kamil, A. C. (1981). Search images and the detection of cryptic prey: An operant approach. In A. C. Kamil \& T. D. Sargent (Eds.) , Foraging behavior: Ecological, ethological, and psychological approaches (pp. 311-331). New York: Garland STPM Press.

Posner, M. I., \& Snyder, C. R. R. (1975). Facilitation and inhibition in the processing of signals. In P. M. Rabbitt \& S. Dornic (Eds.) , Attention and performance (Vol. 5, (pp. 669-682). San Diego, CA: Academic Press.

Reid, P. J., \& Shettleworth, S. J. (1992). Detection of cryptic prey: Search image or search rate? Journal of Experimental Psychology: Animal Behavior Processes, 18, 273-286.

Riley, D. A., \& Roitblat, H. L. (1978). Selective attention and related cognitive processes in pigeons. In S. H. Hulse, H. Fowler, \& S. K. Honig (Eds.) , Cognitive processes in animal behavior (pp. 249-276). Hillsdale, NJ: Erlbaum.

Sutherland, N. S., \& Mackintosh, N. J. (1971). Mechanisms of animal discrimination learning. New York: Academic Press.

Tinbergen, L. (1960). The natural control of insects in pine woods I. Factors influencing the intensity of predation by songbirds. Archives Neerlandaises de Zoologie, 13, 265-343. 